\title{
Representación y delegación de poderes. Los usos públicos del mandato en el ducado de Borgoña (siglos XIII-XIV)
}

Representation and delegation of powers. Political uses of mandate in the duchy of Burgundy (13th-14th centuries)

RESUMO: O presente trabalho trata dos usos públicos da técnica romano-canônica do mandato no ducado da Borgonha durante o século XIII e princípios do século XIV. O artigo tem como objetivo mostrar a centralidade desta técnica na prática de delegação de faculdades e de representação, ambas essenciais para o exercício do governo laico no Ocidente Medieval.

PALAVRAS-CHAVE: Procuração. Delegação de Poderes. Mandato. Ducado da Borgonha. Governo Capeto.

RESUMEN: El presente trabajo trata sobre los usos públicos dados a la técnica romano-canónica del mandato en el ducado de Borgoña durante el siglo XIII y principios del XIV. El artículo tiene como objetivo mostrar la centralidad de esta técnica en las prácticas de delegación de facultades y de representación, esenciales para el ejercicio del gobierno laico en el Occidente medieval.

PALABRAS-LLAVES: Procuración. Delegación de Poderes. Mandato. Ducado de Borgoña. Gobierno capeto.

ABSTRACT: This paper addresses the public uses of the roman-canonical legal technique known as mandatum, as it was effected in the duchy of Burgundy during the 13th and early 14th centuries. The main objective is to show how important this technique was for the delegation of powers and for political and judicial representation, both of which are essential to lay governance in the medieval West.

KEYWORDS: Attorneyship. Delegation of Powers. Mandate. Duchy of Burgundy. Capeto government.

\footnotetext{
* Professor e pesquisador da Universidad Nacional de Costa Rica, Herédia, Costa Rica. Pesquisador da Universidade de Borgonha, Borgonha, França. Doutor em História pela Universidade de Borgonha. E-mail: ajtfauaz@gmail.com http://orcid.org/0003-1862-4025
} 
La representación es uno de los elementos fundamentales a la gobernanza. Está fundada en una delegación de facultades y permite, de arriba hacia abajo, delegar autoridad en un oficial y reducir así el espacio geográfico entre los centros administrativos y los sujetos gobernados.

Inversamente, de abajo hacia arriba, permite delegar en una persona las facultades decisorias y ejecutivas de una colectividad; para que la administre, como es el caso del maior de las comunas urbanas o del presidente de la república; o para que la represente en una asamblea, como es el caso de los comisionados electos por las comunidades religiosas para representarlas en los concilios, o como es el caso, en la modernidad, de las asambleas legislativas y los congresos.

Estudiar la historia de la representación se torna, pues, de mayor importancia, si nos proponemos el objetivo de entender el funcionamiento del poder y las formas particulares de su ejercicio. El interés por estudiar este tema en retrospectiva nunca ha mermado por completo, pero en los últimos años se ha visto avivado por la aparición de varios estudios, como el libro de Arnaud Fossier, le Bureau des Ames (2018), sobre el funcionamiento y la composición política de la Penitenciaría Pontifical en el XIV y el XV, o el libro colectivo dirigido por Mario Damen y Jelle Haemers, Political Representation in Europe, siglos XII al XVII(2018). Además, Frédérique Lachaud y Michael Pennman han codirigido la obra colectiva Absentee Authority in the Medieval West, aparecida el año pasado (2017), lista a la que debe sumarse el volumen editado por Phil Bradford y Alison McHardy, Proctors for Parliament (2017). Probablemente, el precedente más importante de estas obras es el libro dirigido por la misma Frédérique Lachaud, junto con Agnès Berenger, e intitulado Hiérarchie des pouvoirs, délégation de pouvoir et responsabilité des administrateurs dans l'Antiquité et au Moyen Âge, aparecido en 2012.

Es posible identificar una tendencia en estos estudios. Una tendencia, a mi juicio, dichosa, pues consiste en buscar comprender el problema enfocándose en el lugar de conjunción entre la teoría jurídico-filosófica de la representación y su puesta en práctica. En esta óptica, se vuelve clave analizar la técnica jurídica que hace posible la delegación de facultades y, por consiguiente, la representación. Por eso, se han revisitado los trabajos clásicos de Pierre Legendre (1988) y Gaines Post (1965), así como los más recientes de Ludwig Winkel (1993) y de Laurent Mayali (2002), para establecer un punto de partida relativo a las técnicas doctas descritas por el derecho romano clásico y discutidas por el derecho docto medieval. Todos los estudios convergen, entonces, finalmente, en torno al mandato.

El mandato nace como una técnica jurídica que le permite a una persona delegar facultades suyas en un tercero, esto con el fin de que lleve sus asuntos o lo represente en su ausencia. Tiene un origen, por ende, privado, como se deriva de la lectura del Digesto, en específico de Paulus, quien consideraba el mandato como un servicio entre amigos, una suerte de contrato, sin mediar una paga ${ }^{1}$. Este contrato sin embargo tiene límites, pues aquel que ha recibido el mandato, el mandatario, no puede exceder la voluntad, la intención, del mandante. De hacerlo, se expone a la pena del ostracismo, como lo teoriza Gaius ${ }^{2}$ y lo sostienen Ulpiano ${ }^{3}$ y Paulus.

Ludwig Winkel (1993) es quien demuestra que el modelo del mandato privado fue adaptado en tiempos del Bajo Imperio a la administración del Estado. Así, la delegación de facultades individuales sirvió para pensar y posibilitar la delegación de la jurisdictio ${ }^{4}$. Es decir, la posibilidad de que un magistrado delegara las facultades propias de su oficio en un tercero, quien no actuaba en el ejercicio de una jurisdicción propia, sino de una jurisdicción delegada. Se teorizó también el fraccionamiento de la jurisdicción, de tal forma que el magistrado pudiera delegar "partes" de esta a una o varias personas. Esta elaboración se condensa en Ulpiano, quien establece: 
Solet praetor jurisdictionem mandare; et aut omnem mandat, aut speciem unam: et is, cui mandata jurisdictio est, fungetur vice eius cui mandavit, non sua. Praetor, sicut universam jurisdictionem mandari alii potest, ita et in personas certas, vel de una specie potest... ${ }^{5}$

Pensar el mandato de esta manera hizo posible el surgimiento de la figura del mandatum principis, el mecanismo que hacía posible la representación del emperador. Se fundaba, así, la figura del legado imperial, que es el claro modelo del legado pontifical instituido por la Reforma Gregoriana.

Durante la Edad Media, tanto romanistas como canonistas resaltaron el carácter público del mandato. Azón y Martinus discuten su verticalidad y el problema de la representación. El giro práctico se da cuando el papa Eugenio III (1145-1153) intenta justificar la legación apostólica, lo que hace aduciendo que el papa no puede estar en todas partes simultáneamente. Se hace necesario entonces permitir que alguien actúe en representación suya, lo cual se opera jurídicamente por una delegación de facultades mediante mandato. Esto tiene dos consecuencias, por una parte, el mandato se hace equivalente a la representación, pues su justificación canónica requiere de la ausencia forzosa del mandatario. Y, por otra parte, el mandato se transforma en un útil de gobierno, desde el momento en que es utilizado para construir una nueva institución, es decir un nuevo oficio: el del legado pontifical.

A partir de ese momento, las discusiones canónicas se tornan hacia la idea de la procuración, es decir la representación in absentia, al punto que Inocencio III pasa a fundar la naturaleza misma del oficio pontifical sobre ella, haciendo del papa el Vicario de Cristo, es decir su representante in absentia, hasta el día de la Parusía. Pronto, el vicariato pasó a ser fundamento de todo oficio eclesiástico, haciendo que toda prelatura derivara de una delegación de facultades del superior a sus subrogantes. De esa manera, se fundaba toda una teoría del oficio que sirvió de justificación a la jerarquización del clero secular.

Resumo in extremo por razones de espacio, afirmando someramente que sabemos ya algo sobre cómo se desarrolló la teoría del mandato y cómo contribuyó, en el campo jurídico, a la reforma de la institución eclesiástica. Pero apenas comenzamos a entender, gracias a los estudios que cité al principio, de qué manera la delegación y la representación política funcionaban en la práctica. Y en lo que refiere al mundo laico, el panorama está más nublado; apenas se han arrojado, de hecho, unos rayos de luz. En vista de esta situación, me propongo problematizar el uso público del mandato en el gobierno laico y, cuando mejor, establecer algunas generalidades. Para ello, me apoyaré en el estudio de la práctica del ducado de Borgoña, que relacionaré con la práctica de la corona francesa entre los siglos XIII y XIV.

La primera de varias preguntas a responder es si el mandato, de origen docto, fue utilizado en el mundo laico como un medio de delegación de facultades públicas. Y, de ser así, qué usos recibió específicamente. Creo que es exacto responder en positivo la primera pregunta. Mis investigaciones me han mostrado que los duques de Borgoña se sirvieron del mandato para delegar, primeramente, sus facultades judiciales (TOR RES FAUAZ, 2014). Lo hicieron, empero, haciendo uso de una forma específica del mandato que es el mandato especial. Es Rufino de Boloña el primero en distinguir el mandato general y especial ${ }^{6}$. El mandato especial vale para un lugar, tiempo y causa específicos, mientras el mandato general es más amplio. Este carácter restricto del mandato especial lo hacía altamente eficaz como instrumento para la delegación temporal de facultades. Los duques se sirvieron, pues, de él para delegar facultades extraordinarias en los prebostes, permitiéndoles temporalmente actuar en exceso de su jurisdicción. Esta es una técnica descrita por Pierre de Fontaines 
en su célebre Consei $\Gamma$, y la vemos puesta en práctica, por ejemplo, en 1230, cuando el preboste de Châtillon-sur-Seine, Boin de Châtillon, y el preboste de Avallon recibieron un mandato especial del duque Hugo IV para juzgar una causa en la región del Morvand, alrededor de 75 kilómetros fuera de sus jurisdicciones ${ }^{8}$. Luego, entre los años de 1250 y 1280 , varios otros personajes fueron objeto de la delegación de facultades extraordinarias. Martín Chauvin, que era un clérigo de la capilla ducal, aparece juzgando varias causas en distintas regiones del ducado, pero en principio solo era el preboste de Beaune. Así, cada vez que actuaba como juez, se le mencionaba como commendement del duque, es decir, como su mandatario. Otro documento, de 1277, nos muestra al abad de Cîteaux y Jacques de la Roche, preboste de Beaune, encargados de instruir un caso de apelación par especial commandement du duc de Bergoigne.

La técnica del mandato se tornó, entonces, muy útil para hacer llegar la justicia ducal a todas las regiones del ducado mediante la delegación de facultades extraordinarias en varios oficiales, cuya jurisdicción era temporalmente ampliada. El análisis de los documentos sugiere, enseguida, que esa ampliación podía estabilizarse y fundar un nuevo oficio, cuya duración es sin embargo relativa. Por ejemplo, el personaje Boinus, luego de haber visto ampliadas sus facultades, pasó de ser el preboste de Châtillon (viguerius Castellionensis), a ser el vicario del duque, viguerius ducis?. Luego, Lamberto de Rouvres portaría el mismo título, y sería mencionado indistintamente como viguerius ducis o como mandatum ducis, sugiriendo, al ser asimilados ambos distintivos, que la vicaría estaba fundada sobre un mandato. El vicario del duque juzgaba causas en todo el ducado, lo que lo hacía un oficial de justicia de amplísima jurisdicción, pudiendo así descargar al duque de sus obligaciones judiciales mediante la efectuación de un principio de representación.

El vicario ducal es sin embargo mencionado sólo entre 1230 y 1248. Quienes más tarde aparecen portando el singular distintivo de mandatum ducis, son fundamentalmente jueces delegados, mandatados por el duque para juzgar casos en varias regiones del ducado, habiendo recibido un mandato especial. Estas delegaciones parecen ser de distintos tipos y tener diferentes objetivos. Algunas delegaciones concernían a causas ordinarias, como en 1257, cuando Simon de Dijon fue encargado de juzgar una disputa entre los caballeros Hospitalarios y los monjes de Cîteaux, designándosele como mandatum dominus ducis Burgundie per pacem terminandam ${ }^{10}$. Pero otras eran atinentes a casos de apelación. Así, el abad de Cîteaux y Jean de la Roche reciben una delegación de facultades para decidir un caso de apelación presentado por el señor de Nesle contra una sentencia anteriormente pronunciada por el juez delegado Guillaume de Nolay, mencionado también como miles et mandatum ducis. El documento menciona claramente que los jueces de apelación estaban ahí en representación del duque: "lidiz abbés et lidiz prevost sont en leu de lui establi en cette besoigne ${ }^{11}$ ".

Sabemos que la delegación atinente al juicio de causas en primera instancia se estabiliza parcialmente en las figuras de Pierre de Palleau y Guillaume de Nolay, ambos mandatus ducis, que durante un periodo determinado cabalgaron el ducado, conduciéndose públicamente, reuniendo tribunales para celebrar asambleas (asisias), efectuando juicios (placita), y haciendo enmendar las faltas cometidas $(\text { forefacta })^{12}$. Estas acciones invitan a pensar en el oficio de encuestador, conocido para el reino de Francia bajo Luis IX, en la región de Poitou o en el Delfinado durante las décadas de 1240-1260 (CHENARD; LEVASSEUR; CARRIER, 2010). El problema es que es imposible identificar encuestadores de los duques de Borgoña antes de 1306. Y aún entonces, la mención es única, hasta que se torna más recurrente, luego de 1358. Una posible explicación para la ausencia 
de estos encuestadores, suponiendo que no se deba a una laguna documental, es la reorganización territorial - y por ende jurisdiccional - del ducado, que se dividió en bailías, a cuya cabeza había una corte presidida por un nuevo oficial de justicia, el baile, que discutiremos más adelante.

En cualquier caso, es posible constatar, al menos, que el mandato servía a mediados del siglo XIII para instituir oficios judiciales mediante la delegación de la jurisdicción ducal. Delegación que podía alcanzar dimensiones amplísimas y cuya duración era sumamente variable.

A hora bien, en lo que respecta a la delegación atinente a los casos de apelación, el fenómeno de estabilización es un poco distinto. Para entenderlo, debemos trazar una parte de la historia del procedimiento en Borgoña. Antes de 1240, el mecanismo de la apelación no estaba claramente definido en el ducado. Como lo ha sugerido Valérie Toureille (2013, p. 178), la verticalidad implícita en la supremacía señorial de los príncipes (la suzeraineté, en francés), hacía posible que los vasallos insatisfechos recurrieran a sus cortes para revisar la sentencia de cualquier tribunal local. Pero esto no era verdaderamente un procedimiento de apelación. La corte principesca acogía la causa como si fuera una causa nueva y hacía un nuevo juicio, cuya resolución debía imponerse sobre la primera sentencia en virtud de la supremacía del señor justiciero. En Borgoña, sólo luego de 1240 lentamente fue definida la apelación, al sistematizarse el procedimiento romano canónico en todas las cortes de jurisdicción ducal. Desde entonces, se partía de la primera sentencia, se revisaba su forma y, si era necesario, se revisaba el fondo, procediendo finalmente a anularla o a corroborarla.

El perfeccionamiento del mecanismo de apelación aumentó el flujo de este tipo de causas a la corte del duque. Entre 1240 y 1280, su resolución fue encargada al Parlamento Ducal, que, inundado de apelaciones, procedió sistemáticamente a delegar su jurisdicción en varias personas que, actuando como jueces delegados, se encargaban de revisar las sentencias originales, de hacer comparecer a las partes y de pronunciar una sentencia definitiva. Luego de 1280, se crea una nueva institución, el Auditorio de Causas de Apelación, que está atado al Parlamento hasta autonomizarse en el año de 1315 (CHAMPEAUX, 1908, p. lxx-xc; RICHARD, 1957, p. 437-441). En el proceso de autonomía, los antes jueces delegados se transformaron en auditores de apelación, un nuevo oficio, fundado igualmente en una delegación de facultades, como se lee en la primera colección de costumbres del ducado, el Costumario borgoñón de Montpellier, escrito en 1315, donde se indican que los auditores pueden tener un mandato especial o un mandato general, y eso determina la posibilidad de apelar sus sentencias ${ }^{13}$. Valga mencionar que esa manera de concebir el oficio del auditor está en concordancia con los principios establecidos por el derecho canónico, específicamente en Guillermo Durando, quien asimilaba los oficios de auditor, procurator y executor pontificales, todos fundados en una delegación de facultades mediante mandato ${ }^{14}$.

Es, desde ya, posible constatar la importancia del mandato en el ejercicio del gobierno de los duques y en la construcción o reformación de las instituciones del ducado durante el siglo XIII.

\section{Procuración y lugartenencia}

Pero el mandato era también utilizado con otros objetivos dentro del gobierno ducal, específicamente en lo relativo a la representación in absentia. Una de las formas de la representación, quizá la más común, es la procuración. La primera vez que el duque de Borgoña intentó hacerse representar por un procurador fue en 1153, ante su señor ligio, quien sin embargo lo declaró contumaz, pues no era entonces aceptado que alguien se hiciera representar en la corte de su señor ${ }^{15}$, 
como ha sido demostrado por muchos autores, desde el clásico Heinrich Brunner hasta el más reciente John Baldwin. Sin embargo, desde la segunda mitad del siglo XII, el duque reconocía a los monasterios y a las comunas el derecho de hacerse representar en su corte por un procurador. Este principio se generalizó en el ducado hasta ser incluido en las costumbres de Dijon (PETITJEAN, 1983, p. 25-37), de finales del siglo XIII, donde se lee: "Il est coustume, que nuls ne plaidiera par procureur en cort laie, se n'est chapitres ou covanz ou colleiges.” ${ }^{\prime 6}$

Ahora bien, aunque no sea posible identificar procuradores del duque de Borgoña que fueran a representarlo en otras cortes, donde rara vez figura como actor durante la segunda mitad del siglo XIII, sí es posible constatar una forma de representación instituida mediante mandato, a saber la lugartenencia. La institución en la que debemos concentrar nuestra atención es el Parlamento Ducal, consolidado entre 1275 y 1305 . Sabemos que durante este periodo, el Parlamento debía ser presidido por el duque, mas no son raras las ocasiones en que lo preside algún lugarteniente, que declara explícitamente estar ahí en representación del duque (PAILLOT, 1642; PLANCHER, 1664, p. 145-160; LAMEERE, 1900, p. 126; RICHARD, 1957, p. 437-441, 481) ${ }^{17}$. Ya aquí es perceptible la efectuación de una delegación de facultades, por lo que no es extraño identificar como remplazos del duque a los mismos personajes que reciben en otras ocasiones un mandato especial para juzgar alguna causa en nombre del duque, como Guillaume de Nolay que presidió el parlamento en 1280 y juzgó causas como mandatum ducis entre 1269 y 1277.

Por otra parte, existe una relación entre la lugartenencia a la cabeza del Parlamento y la guardia del sello de jurisdicción graciosa del duque. Este sello, aparecido en la década de 1270, es un medio de legitimación pública de un acta; su aposición era solicitada por las partes, que a cambio pagaban una suma de dinero (BOÜARD, 1910 $)^{18}$. En principio, el documento legitimado debía pasar por los ojos del duque, quien lo sellaba dándole valor. Pero la multiplicidad de tareas que concentraba la curia ducal, condujo al duque a delegar la guardia de su sello a un tercero, que en un primer momento fue su canciller, el cual debía encargarse de comprobar la justeza del documento, imprimir el sello de jurisdicción graciosa, recibir el pago por este servicio y transmitirlo al tesoro ducal. Es claro, entonces, que el oficio del guardián del sello está fundado en una delegación de facultades, ficción que le permite al guardián sustituir los ojos del duque por los suyos (CAROLUS-BARRÉ, 1935, p. 5-48; RICHARD, 1957, p. 475-521). Por eso, no es difícil entender que la efectuación de esta ficción pudiera trasladarse a otro contexto, haciendo del guardián del sello un candidato recurrente para suplir al duque frente al Parlamento. Un ejemplo concreto se nos ofrece en la figura de Jean de Semur, archidiácono del convento de Flavigny, quien fue canciller del duque entre 1279 y 1291, tiempo en el que actuó como guardián del sello de jurisdicción graciosa, antes de pasar a presidir, en múltiples ocasiones, las sesiones del Parlamento ducal en representación del duque $^{19}$. Importa señalar que esta transición es también común en la práctica de los bailes reales en la región de Champaña, como lo demuestra Robert Bautier en un artículo ya clásico, donde identifica varios personajes que fueron, en un primer momento, guardianes de los sellos de jurisdicción graciosa de los bailes reales, antes de pasar a actuar regularmente como sus lugartenientes (BAUTIER, 1958, p. 51-55).

Es importante dejar claro que no únicamente los duques podían hacerse representar mediante mandato en el mundo laico. Tanto a los bailes como a los prebostes se reconocía esta capacidad, codificada en el Digesto ${ }^{20}$ y retomada por el Livre de Jostice et de Plet, volumen compuesto en la década de 1260 y reflejo de la enseñanza de la Escuela de Orléans, donde se lee: 
Li prévoz puet mender sa juridiction, ou toute, ou une pièce : car cil à qui la juridiction est mandée n’use pas de sa [propre] juridiction, mès de cele à celi qui la li mande. Ausint com li baillis ou li prévoz puet mander sa juridiction tote, ausie en puet-il mander partie ${ }^{21}$.

O todavía "Li baillis pot baillir sa juridiction à un autre, ou mander; mès li autre ne la puet baller à autre ne envoier". 22

Hacia finales del siglo XIII encontramos varios casos en que los bailes ducales se hacen suplir en sus cortes por lugartenientes, por ejemplo, en 1295 se menciona a Pierre Ynglot como leutenant del baile de Dijon, quien preside, bajo ese título, una sesión de la corte de bailía ${ }^{23}$. Esto se repite en 1297, cuando el baile de Dijon delega en el preboste de Beaune, Robert de Brezey, la presidencia de su corte, durante la sesión tenida en Nuits-Saint-Georges ${ }^{24}$. En la misma época encontramos al preboste ducal de Saint-Loup, una pequeña comunidad, haciéndose representar por Estienne, "clerc, commandement a prevost de Saint Lou", quien preside la corte local para juzgar una causa entre el priorato de Combertault y el señor Guillaume de Beaune ${ }^{25}$.

Estos ejemplos muestran que la técnica de representación mediante mandato estaba en uso en varios niveles de la administración ducal. Se trata, pues, de un útil de gobierno altamente eficaz y considerablemente generalizado para inicios del siglo XIV. Puede, así, afirmarse que el gobierno ducal se ejercía, al menos en parte, mediante la representación, sobre todo en lo atinente a lo judicial. La prueba está en las figuras de los jueces delegados, los auditores y los lugartenientes, tanto de los duques como de los oficiales subalternos, quienes ejercían todo un conjunto de oficios fundados en la delegación de poderes, haciendo posible la administración de la justicia en el ducado.

Cabe afirmar en este momento que lo que vale para la administración del ducado de Borgoña parece también valer para la administración del reino francés. Desde 1208 encontramos al caballero Itier de Toucy, mencionado como Philipis regis Francie in Burgundia vicarius, quien, en nombre del rey, juzgaba causas en Borgoña, haciendo, por ejemplo, comparecer al obispo de Mâcon sobre la tenencia de la casa de Boy. Más adelante, en 1269, el rey Luis IX encarga una encuesta para determinar si su procurador en la bailía de Mâcon, Lambert de Chateauneuf, había actuado en exceso de sus facultades al confiscar en nombre del rey las tierras de la viuda de Bois. Un poco más tarde, en 1271, el abad de Clermont y Nicolás de Catalano, un clérigo del rey, actúan como jueces delegados, de speciali mandato domini regis, Felipe III, con el fin de solucionar un conflicto entre el obispo de Autun y los burgueses de Lyon. Y finalmente, en 1308, el rey encarga al baile de Mâcon de juzgar una causa entre su procurador y el señor de Beaujeu, para determinar si aquél ha excedido su procuración.

No es raro, además, encontrar en las cartas de comisión reales la fórmula: "De toutes les choses dessus dites et chascune dicelles faire, vous donnons pooir, auctorité et mandement spécial par la teneur de ces présentes”. Esta fórmula merece nuestra atención, pues obtiene tal estabilidad que puede encontrarse entre los siglos XIV ${ }^{26}$ y XVII ${ }^{27}$, en las llamadas cartas patentes de comisión reales.

Además, encontramos en los documentos a sargentos y lugartenientes de los bailes reales, de Sens, de Mâcon, así como del oficial de Couches, una comunidad pequeña pero importante, en la diócesis de Autun. Esto corrobora nuestra idea de que las técnicas de la delegación y la representación participaban del gobierno de los reyes a todos los niveles. 


\section{¿Eran el baile y el preboste mandatarios?}

En la última parte de este artículo, quisiera regresar al problema de la estabilización de las facultades y jurisdicciones delegadas, para discutir la posibilidad de que el mandato haya servido para fundar la autoridad de un oficial importantísimo para la organización y jerarquización de las estructuras administrativas laicas en el reino de Francia, a saber: el baile.

El baile es fundamentalmente un oficial de justicia, cuya jurisdicción está bien definida y cuyo ejercicio se realiza desde la presidencia de una corte, a la cual están subordinadas las cortes de los prebostes. Sabemos que el baile ejerce su oficio durante un periodo limitado. En Borgoña, son tres años, según lo demostró el historiador Yves Tripier (1974). Sin embargo, no es claro el medio por el cual el baile obtiene su autoridad. Aún no se ha respondido en definitiva cuál es el fundamento de su oficio.

Jean Boutillier, autor de la Somme Rurale, distingue tres tipos de jurisdicción. La primera es una jurisdicción natural, la segunda es una jurisdicción ordinaria y la última una jurisdicción cometida, es decir delegada. La jurisdicción natural deriva del derecho señorial, la jurisdicción ordinaria es propia de los oficiales que reciben paga ordinaria o beneficio, como los castellanos. Pero la jurisdicción delegada tiene origen en una cesión de facultades, y no deriva de ninguna dignidad ${ }^{28}$.

Esto se completa con lo expresado por Ulpiano: "is, cui mandata jurisdictio est, fungetur vice eius cui mandavit, non sua" ${ }^{29}$, pasaje que fue traducido en el Livre de Jostice et de Plet: "cil à qui la juridiction est mandée n'use pas de sa [propre] juridiction, mès de cele à celi qui la li mande" 30 . Esto quiere decir que el mandatario, o comisionado, no tiene una jurisdicción propia sino que actúa vice, bajo, la jurisdicción de aquél que se la ha delegado, toda o en parte.

Basado en estos dos preceptos, el historiador Romain Teillez (2012) ha argumentado que el mandato no puede fundar un oficio, pues no crea magistratura. En lo último tiene razón, sin embargo, los ejemplos de la práctica y otros textos normativos muestran que varios oficios están claramente fundados en una delegación jurisdiccional, como la legación pontifical. Así, "Legatus domini pape interest et non vice ordinarie potestatis, set vice plenarie potestatis domini pape..."31.

También el oficio de los sargentos, como lo describe el mismo Jean Boutillier:

Sergens par l'ordonnance de raison escrite, et par la constitution des faiteurs de loix, sont commis par le Iuge de executer les exploits et commandemens dudict Iuge, et representent le faict du seigneur en exerçant leur office de sergenterie ${ }^{32}$.

Este es también el caso de los auditores, como lo mostré más arriba. No queda, pues, claro si el mandato pudo servir para instaurar oficios de carácter más permanente, como los bailes o prebostes - que sin embargo tampoco eran propietarios del título, como lo afirmé antes. La duda se instaura, sobre todo, cuando en los Établissements de San Luis, específicamente en la Ordenanza de 1254, el rey afirma que los prebostes y los bailes tienen su oficio por comisión:

Si jurront doncques tous ceux devans dis, et chacun d'eux, tant comme ils tendront par commission baillie, prevosté, ou autre quelconque office devant dit, il feront et rendront droit aussi aux gregneurs comme aux mayeus... ${ }^{33}$ 
No deja de pesar también el hecho de que los bailes hacen su aparición hacia mediados del siglo XIII, cuando la técnica del mandato estaba ya en uso por los reyes y los duques para la delegación de su jurisdicción. La pregunta si el mandato fue la técnica mediante la cual se creó el oficio del baile y se reformó el del preboste, se vuelve entonces capital, y está aún irresoluta. No será definitivamente en este espacio en el que le demos una respuesta convincente, pero al menos vale la pena sembrar la duda.

Si el baile y el preboste fueran comisionados, eso implica que actuaban en representación de y vice la jurisdicción del príncipe, lo cual haría del mandato uno de los útiles fundamentales a la jerarquización de las instancias y de los oficios en el mundo laico. Esto ha sido ya demostrado para el reino de Inglaterra, por Frédérique Lachaud (2010), y para el Sacro Imperio, por Pierre Legendre (1988), pero aún queda por resolverse para el territorio francés. Los ejemplos de la práctica nos permiten constatar que existía en efecto una jerarquía entre las cortes laicas. Un caso en particular resulta muy ilustrativo, tanto más pues en todos los momentos se efectúa el principio de la representación. Veamos:

En 1296, el lugarteniente del preboste de Saint-Loup juzga un pleito iniciado por el procurador del señor Guillermo de Barrot contra los monjes de Combertault, que se hacen también representar por un procurador ${ }^{34}$. El pleito es por la confiscación del aspa de un molino. La corte prebostal falla a favor de los monjes. Guillermo entonces eleva la causa, es decir la apela, ante la corte del baile de Dijon. Aquí identificamos un primer escalón en el edificio de instancias. Los monjes arguyen sin embargo no haber sido convocados con suficiente antelación, entonces presentan una segunda apelación ante el Parlamento ducal, que asigna dos jueces delegados para ver el fondo del asunto. Segundo escalón. Los jueces de apelación revisan el caso y fallan a favor de los monjes.

Pero Guillermo no está satisfecho. Arguye, con razón, que los jueces de apelación no estaban suficientemente instruidos, es decir que no conocían el fondo del asunto sobre el que se pronunciaron. Debían haberse limitado a definir si el plazo de convocatoria había sido suficientemente largo. Lesionado, Guillermo se dirige a una instancia paralela: a la corte del preboste de Beaune, y presenta ahí el reclamo contra la sentencia de los jueces delegados. Enterados del asunto, los jueces emiten una carta en donde amenazan al preboste de Beaune de imponerle una multa de 20 sólidos si acoge la causa y pronuncia sentencia.

Este caso muestra de manera muy evidente que el edificio de instancias en el ducado se escalonaba al menos en dos niveles, las cortes de los prebostes en el nivel más bajo, la de los bailes en el medio y el Parlamento ducal en lo más alto. Pero lo más interesante es menos evidente. ¿Por qué medio se escalonaban las cortes? Yo quisiera proponer que esta jerarquización es efecto del hecho que todas las instancias compartían una sola y única jurisdicción, la del duque, quien mediante una delegación fundaba todos los oficios judiciarios directamente subordinados a su curia y al Parlamento ducal. Esto se hacía mediante un fraccionamiento jurisdiccional que permitía que las fracciones delegadas no se entremezclaran, pudiendo así dividir de manera exacta el territorio ducal en 4 bailías y estas en un número determinado de prebostías.

Con respecto al fraccionamiento, puede seguirse a Ulpiano: "Praetor, sicut universam jurisdictionem mandari alii potest, ita et in personas certas, vel de una specie potest". ${ }^{35}$

Texto retomado por Li Livre de Jostice et de Plet: "Li prévoz puet mender sa juridiction, ou toute, ou une pièce [...] Ausint com li baillis ou li prévoz puet mander sa juridiction tote, ausie en puet-il mander partie". ${ }^{36}$ 
Este principio parece apoyar la posición de Jean Boutillier, con respecto a la inflexibilidad de la jurisdicción delegada:

[...] se peut le sergent avancer à prise et à detention de corps dessous quelque iurisdiction que ce soit, pourtant que ce soit terme de Bailliage dont il est sergent, autrement non.

Item ne peut ou doit un servent d'autre bailliage faire ne exercer office en autre bailliage, s'il na sur ce committimus du Roy de ce faire qui contienne le cas: et convient que le sergent qui ce voudroit faire, montrast au Baillif sur qui il vient executer son mandement... ${ }^{37}$

El último párrafo, de Jean Boutillier, invita a pensar en algo más, en que la jurisdicción siempre remite al príncipe, pues este, mediante un mandato especial, puede facultar a un sargento, es decir a un comisario, a actuar dentro de los límites de una jurisdicción que, si se corrobora mi idea, le habría sido delegada ordinariamente a otro oficial, a un baile, quien, no siendo estrictamente el superior del dicho sargento, estaría por encima de él en la jerarquía judicial.

Todo invita a pensar que tales excepciones hacen eco del principio establecido por Simón de Bisigniano, a saber: el mandato especial deroga el mandato general ${ }^{38}$. Con ello estaríamos afirmando que bailes y prebostes fundaban su oficio en un mandato general del príncipe, actuando así en su representación.

Si nos remitimos nuevamente al caso de apelación borgoñón, notamos que, vista en esta lógica, la multa con la que se amenaza al preboste de Beaune, de 20 sólidos, penaliza el exceso de su jurisdicción, es decir un exceso de mandato.

Referir más ejemplos en el mismo sentido daría la impresión de buscar la erudición gratia ea. Quisiera entonces concluir, no resumiendo lo ya expuesto, sino enfatizando en la importancia de la última pregunta que he lanzado. Si se lograra determinar que la técnica de delegación de facultades sirvió a los príncipes para crear oficios y para jerarquizarlos, sofisticando así sus estructuras de gobierno, nos vemos más que nunca obligados a replantear el carácter exclusivamente feudal de los principados franceses y del reino durante los siglos XIII y XIV. Viéndonos así forzados a pensar más que nunca en la importancia de la pluralidad jurídica en la organización y en el ejercicio del gobierno en esta época, como lo había planteado brillantemente la profesora María Filomena Coelho (2018, p. 133-150) en Costa Rica hace dos años. No se trata, claro está, de sobredimensionar el aporte del derecho docto y ensombrecer la importancia de la costumbre y del derecho feudal, sino entender de qué manera todas estas dimensiones jurídicas coexistieron y sirvieron a diferentes objetivos en el marco de la sofisticación de los gobiernos real y principesco.

Cuando prestamos suficiente atención a la delegación de poderes, nos damos cuenta de cuán esencial fue durante los últimos años de la Edad Media y durante la Modernidad, para permitir el funcionamiento del aparato público de los estados reales y prontos monárquicos. La delegación es por ejemplo el fundamento de la figura del gobernador y también de la figura del virrey, que fueron figuras determinantes cuando los reinos medievales crecieron hasta devenir imperios modernos y llegar a las costas de este continente, que conquistaron y dominaron, con el espíritu bien anclado en la Edad Media. 


\section{Referências}

BAUTIER, R.-H. L'exercice de la juridiction gracieuse en Champagne du milieu du XIIle siècle à la fin du XVe. In: BIBLIOTHEQUE de l'école des chartes. t. 116. 1958. p. 29-106.

BOÜARD, A. de. Études de diplomatique sur les actes des notaires du Châtelet de Paris. Bibliothèque de l'École de Chartes, fasc. 186. 1910.

BRADFORD, P.; MCHARDY, A. (ed.). Proctors of Parliament: clergy, community and policy. Woodbridge: Boydell, 2017.

CAROLUS-BARRE, L. L'ordonnance de Philippe le Hardi et l'organisation de la juridiction gracieuse. In: BIBLIOTHEQUE de l'école des chartes. t. 96.1935. p. 5-48.

CHAMPEAUX, E. Les ordonnances des ducs de Bourgogne sur l'administration et la justice du Duché. Dijon: Université de Dijon, 1908.

COELHO, M. F. Um universo plural: política e poderes públicos na Idade Média (séc. XII-XIII). In: TORRES FAUAZ, A. (ed.). La Edad Media en perspectiva latinoamericana. Heredia: EUNA, 2018. p. 133-150.

DAMEN, M.; HAEMERS, J. (ed.). Political Representation: Communities, Ideas and Institutions in Europe (c. 1200-1690). Leiden: Brill, 2018.

DEJOUX, M. Les enquêtes de Saint Louis. Paris: PUF, 2014.

FOSSIER, A. Le bureau des âmes. Écritures et pratiques administratives de la Pénitencerie apostolique (XIII'-XIVe siècles). Roma: EFR, 2018.

LACHAUD, F.; BERENGER, A. (ed.). Hiérarchie des pouvoirs, délégation de pouvoir et responsabilité des administrateurs dans l'Antiquité et au Moyen Âge. Metz: CRULH, 2012.

LACHAUD, F.; PENNMAN, M. (ed.). Absentee Authority across medieval Europe. Suffolk: OUP, 2017.

LAMEERE, E. Le grand conseil des ducs de Bourgogne de la maison de Valois. Bruxelles: Alfred Castagne, 1900.

LEGENDRE, P. Du droit privé au droit public. Nouvelles observations sur le mandat chez les canonistes classiques. In: LEGENDRE, P. Écrits juridiques du Moyen Âge occidental. Londres: Ashgate, 1988. p. 7-34.

MAYALI, L. Procureurs et représentation en droit canonique médiéval. In: Mélanges de l'École Française de Rome. Moyen Âge, v. 114, n. 1, 2002. p. 41-57.

PALLIOT, L. Le Parlement de Bourgogne. Dijon, 1642.

PECOUT, T. (ed.). Quand gouverner c'est enquêter, Paris: De Boccard, 2010.

PETITJEAN, M. La formation de la coutume de Bourgogne et l'enseignement du droit à Beaune à la fin du XIVe siècle. Recueil de Travaux du Centre Beaunois d’Études Historiques. 1983. p. 25-37. t. 4.

POST, G. Studies in medieval legal thought. Public law and the State. 1100-1322. Princeton: Princeton, 1964.

RICHARD, J. Les ducs de Bourgogne et la formation du duché du Xle au XIVe siècle. Paris: Les Belles Lettres, 1957.

TEILLEZ, R. Sous ombre de son office, délégation du pouvoir royale et responsabilité des officiers en France à la fin du Moyen Âge. In: LACHAUD, F.; BERENGER, A. (ed.). Hiérarchie des pouvoirs, délégation de pouvoir et responsabilité des administrateurs de l'antiquité au Moyen Âge. Metz: CRULH, 2012. p. 291-309.

TRIPIER, Y. Les baillis ducaux bourguignons, leurs attributions et leur compétence judiciaire: le tribunal baillival, son organisation et son fonctionnement (1262-1477). Rennes: [s.I.], 1974.

TORRES FAUAZ, A. Pouvoir princier et pratiques judiciaires. La généralisation des enquêtes dans le duché de Bourgogne, XIle-XIIIe siècle. Dijon: Université de Dijon, 2014.

TOUREILLE, V. Crime et châtiment au Moyen Âge. Paris: Armand Collin, 2013.

WINKEL, L. Mandatum in öffentlichen romanischen Recht? In: NÖRR, D.; NISHIMURA, M. (ed.). Mandatum und Verwandtes. Beiträge zum römischen und modernen Recht. Berlin; Heidelberg: Springer, 1993. p. 53-65. 


\section{Notas}

${ }^{1}$ Paulus, Liber 32 ad edictum, Dig. 1, 17, 1.

${ }^{2}$ ad Inst. 3, 161.

${ }^{3}$ D., $3,1,1,2$.

${ }^{4}$ D. $1,21$.

${ }^{5}$ D. 2, 16-18.

${ }^{6}$ Rufinus, ad Decretum Gratiani, dist. 17: Auctoritas vel licentia aliquando generalis, aliquando specialis intelligitur. Deinque generalis auctoritas vel licentia est indulta, ut post modum semper licite exerceri valeat pro tempore, loco et causa...

${ }^{7}$ Le conseil de Pierre de Fontaines, ed. M. Marnier, Paris, 1846, caput XXVIII, art. XIV, p. 372: “Ne cil à qui li roi commande a oïr, na nul pooir d'enjoindre la paine, s'il ne li est ostroié especialment...”; Ibid., art. XVIII, p. 375-376: “...à ceus qui tienent en baronies en lor baillies doivent-il amender, se en se pleint à els qu'ils ostent les forces, et facent rentériner les desseisines; et s'il ne le font fère, le pueent li baillif: mès ès baronnies qui sont ès parties de France, ne pueent-il riens manovrer fors par le commandement le roi espécial; car tels persones ne respondent de n'els ne de lor terres, fors par le roi".

${ }^{8}$ Cartulario de la Moutiers-Saint-Jean en Réomans, ed. Roverius, P., Reomaus, seu historia monasterii S.-Joannis reomaensis, in tractu lingonensi, primariae inter gallica coenobia antiquitatis, ab anno Christi CCCCXXV, Paris, 1637, n. 14 (AD 1230): Ego Hugo Dux Burgundiæ notum facimus omnibus præsentes litteras inspecturis, quod in præsentia Andreæ Domini Espissiæ, \& mandati nostri à nobis constituti, videlicet Boini Vigerij Castellionis, \& Petri de Corbigny Præpositi Aualonis, loannes de Vineis, \& filij eius, videlicet Andreas, Nicolaus Clericus, Hugoino \& Achardus, \& omnes alij hæredes sui quitauerunt Ecclesiæ Reomaensi spontanei, non coacti, absque vlla reclamatione, quidquid iuris se dicebant habere in omni vtilitate in villa de Soanceio cum appendiciis suis, \& in finagio eiusdem villæ, si quid iuris in eodem habebant.

${ }^{9}$ Archives Départementales de la Côte d’Or (ADCO), Cartulaire 201, Fontenay, fol. 134 r ${ }^{\circ}$ (1233).

${ }^{10}$ ADCO $11 \mathrm{H} 66$ (Cart. 168), f. 45 v․

${ }^{11}$ ADCO $15 \mathrm{H} 130$.

${ }^{12}$ Autun, Eg., 143 (1269): [...] dicti milites gerebant se publice in tota Burgundia pro duce in tenendo asisias et placita et faciebant emendari forefacta que perpetrabantur in Burgundia.

${ }^{13}$ Le Coutumier Bourguignon de Montpellier, éd. E. Champeaux, Dijon, 1908, § 60 et 2, De l'appel devant les auditeurs.

${ }^{14}$ Guillaume Durand, Speculum... op. cit., pars $3^{\text {a }}$, ed. Lyon, 1576, p. 143.

${ }^{15}$ Me refiero al conocido proceso de Moret, de 1153, en que el duque Odo Il quería hacerse representar en justicia por un procurador ante el obispo de Langres. Éste no aceptó dicha representación como un principio legítimo, lo que fue ratificado por Luis VII, Cf. Cartulaire de l'évêché de Langres, ed. Flammarion, $n^{\circ} 119$.

${ }^{16}$ PÉRARD, Étienne. Recueil de plusieurs pièces curieuses servant à l'histoire de Bourgogne. Paris, 1664. p. 358.

${ }^{17}$ ADCO B 312, fol. 9: En el año de 1280, “monsiere de Nolay, Magistre Jean de Blanot et maistre Hugon d'Arce [...] tenirent les jours à Beaune, que Miessires [le duc] n'i pout estre"; ADCO 11H 409: En 1298, "Nos Roberz de Braise, tenanz le sege por mon saignor le duc a Nuyz...”; ADCO B 1323: En 1305, en ausencia del duque Roberto II, fue Jean de Semur, canciller del duque, quien presidió la sesión plenaria del Parlamento.

${ }^{18}$ Esta acción fue regulada, a nivel del reino francés, por una ordenanza de Felipe III, perdida, datada entre 1279 y 1283 , cuya principal referencia se encuentra en las Coutumes de Bauvaisis, de Philippe de Beaumanoir.

${ }^{19}$ ADCO B 312, fol. 90. En 1280, “monsiere de Nolay, Magistre Jean de Blanot et maistre Hugon d'Arce [...] tenirent les jours à Beaune, que Miessires [le duc] n'i pout estre”. Igualmente, en 1305, una sesión de las Jornadas Generales del Parlamento es presidida por el canciller del duque, Jean de Semur, en ausencia del duque Roberto II, ADCO B 1323 (1305), situación que se repite en varias ocasiones durante esa década, ADCO G 960.

${ }^{20}$ Dig, 2, 1, 16-17: “Solet praetor jurisdictionem mandare; et aut omnem mandat, aut speciem unam: et is, cui mandata jurisdictio est, fungetur vice eius cui mandavit, non sua. Praetor, sicut universam jurisdictionem mandari alii potest, ita et in personas certas, vel de una specie potest...".

${ }^{21}$ Li Livres de Jostice et de Plet, ed. P. Rapetti, Paris, 1850, Lib. 2, §11, p. 138.

22 lbid., §8.

${ }^{23}$ ADCO 1H 1600

${ }^{24}$ ADCO 11H 409. 
${ }^{25}$ ADCO $1 \mathrm{H} 1600$.

${ }^{26}$ ORF, t. 4, p. 151 (28 jul. 1354).

${ }^{27}$ BNF D2 RdJ, F-46902 (10), “Lettres de commission à François Pithou, en qualité de procureur général, pour la recherche des malversations en matière de finances", fuente impresa.

${ }^{28}$ Boutillier, Somme Rurale, ed. Paris, 1603, p. 9.

${ }^{29}$ Dig. 2, 1, 16.

${ }^{30}$ Li Livres de Jostice et de Plet, ed. P. Rapetti, Paris, 1850, Lib. 2, §11, p. 138.

${ }^{31}$ Distinctiones, Cambridge Addit. 3321, fol 40vº, cité par Legendre, op. cit., p. 31.

32 BOUTILLIER, Jean. Somme Rurale. Des sergens, Paris, 1603. p. 667.

${ }^{33}$ DE LAURIÈRE, M. (éd.). Recueil des Ordonnances des rois de France. t. I. Paris, 1723. p. 67.

${ }^{34}$ ADCO $1 \mathrm{H} 1600$.

${ }^{35}$ Dig. 2, 1, 16.

${ }^{36}$ Li Livres de Jostice et de Plet, Lib. 2, §11, p. 138.

${ }^{37}$ BOUTILLIER, Jean. Somme Rurale. Paris, 1603. p. 667-668.

${ }^{38}$ Summa decreti, BNF 3934A, fol. 66 v $^{\circ}$. 